\title{
Analysis and Design of Data Resource Management System for Jinshandian Iron Mine
}

\author{
http://dx.doi.org/10.3991/ijoe.v11i8.4876 \\ YunSen Wang \\ Northeastern University, Shenyang, China
}

\begin{abstract}
With the development of enterprise information, data resources have become one of the most important assets of enterprises. This paper summarizes the current problems of data resource management for the Jinshandian Iron Mine and then analyzes the areas of standards, organizations, systems, processes and management tools. It provides an implementation guide and presents the problems that were faced in practice with the recommended solutions. The results of a practical application show that it has significance for implementing a data resource management system of mine enterprises.
\end{abstract}

Index Terms-Data resource management, Data mining, Data management

\section{INTRODUCTION}

Traditionally, human resources, financial resources and materials are the three key assets for an enterprise. As enterprise information construction has grown, the whole operation has gradually been become digital [1]. A large amount of data is generated from various information systems within the enterprise network. These data can be used to make better decisions, reduce operation risks, and help enterprises adapt to the changing market competition environment to gain maximum economic benefits. This has caused the data resources of enterprises to join the ranks of human resources, financial resources and materials and become one of the most important assets of the enterprises.

With the emergence of the mobile internet, big data and cloud computing, etc. data resources within an enterprise will be flat. As the new important assets of enterprises, data resources effectively support the development of the enterprises and improve the competitiveness of the enterprises. By improving data transparency and information resources, a data resource can achieve mastery of data within the enterprise to strengthen collaboration and to help enterprises effectively reduce operational costs $[2,3,4]$.

The mining industry is a pillar of the industrialization of the country and an important part of the national economy. Data resources arising from the mining industry can be important indicators of future economic forecasts and can be used to effectively create new values $[5,6]$. In this view, data are not only the value of the enterprise itself, but also a certain asset for businesses and the national economy.

\section{STATUS OF DATA RESOURCES IN JINSHANDIAN IRON}

The Jinshandian Iron Mine is in Daye City, Hubei Province, with railway transport of $13 \mathrm{~km}$ from Iron Mountain and $91 \mathrm{~km}$ from Wuhan Steel. In 1979, the Zhang Fu Shan area was built and piloted production. In 1988, it was formally put into production with a capacity of 100 million $\mathrm{t} / \mathrm{a}$.

The Jinshandian Iron Mine has high motivation in digital mine building, having planned and implemented major information systems: a large-screen video surveillance system, a micro-seismic monitoring system, a traffic control system, a mine online automatic measurement and management of transport system, and remote automation of a ventilation and drainage control construction requirements system. The main software systems are SURPAC Software, logistics software, financial management software, and Office automation systems, etc. The Jinshandian Iron Mine has not built up an underground network. And it has 850 PCs and 20 Servers with an intranet bandwidth of $100 \mathrm{M}$ option.

The Jinshandian Iron Mine has accumulated valuable information construction and operation experiences in the process of creating information systems and infrastructure resources and has established an information technology team. But the independence of these respective systems has caused "an information isolated island.". Consequently it is currently at the stage of technical support providers.

After two months of investigation, the problems of the Jinshandian Iron Mine's data resources were summarized as the following four areas:

1) There was more than one entry for the same data; supplier data from financial accounting, materials management, the project management system cannot be shared.

2) There was no agency to clarify the business relationships among materials, projects, contracts.

3) There was a lack of uniformed data standards. For example, for the supplier data, each definition was inconsistent among the systems.

4) Currently, there was a lack of a unified view of the data for guidance to ensure future IT systems, integration, and business process optimization.

This suggested that the Jinshandian Iron Mine has low capability in overall data quality and data integration. The lack of comprehensive construction and management work in data standards, data quality, data security, data platforms has caused the data quality to be the most highlighted. Consequently, data integration and data accuracy, data consistency, data collection rules cannot meet busi- 
PAPER

Analysis and Design of Data Resource Management System for Jinshandian IRON Mine

ness fusion and integration of required information. Therefore, in the future, the information work should promote special data projects for the continuous improvement of data quality and data utilization to improve information control and the operating modes and to continue to drive up the overall development level of informatization.

\section{ANALYSIS OF WORKFLOW AND BUSINESS DATA RESOURCES}

The 15 main business processes of the Jinshadian Iron Mine summarize the present situation and problems. The main processes contained geological prospecting, mining exploration, mine design, mine infrastructure, mining. Mining production was mainly involved in mining geology, mining, and mineral processing, as shown in Figure 1.

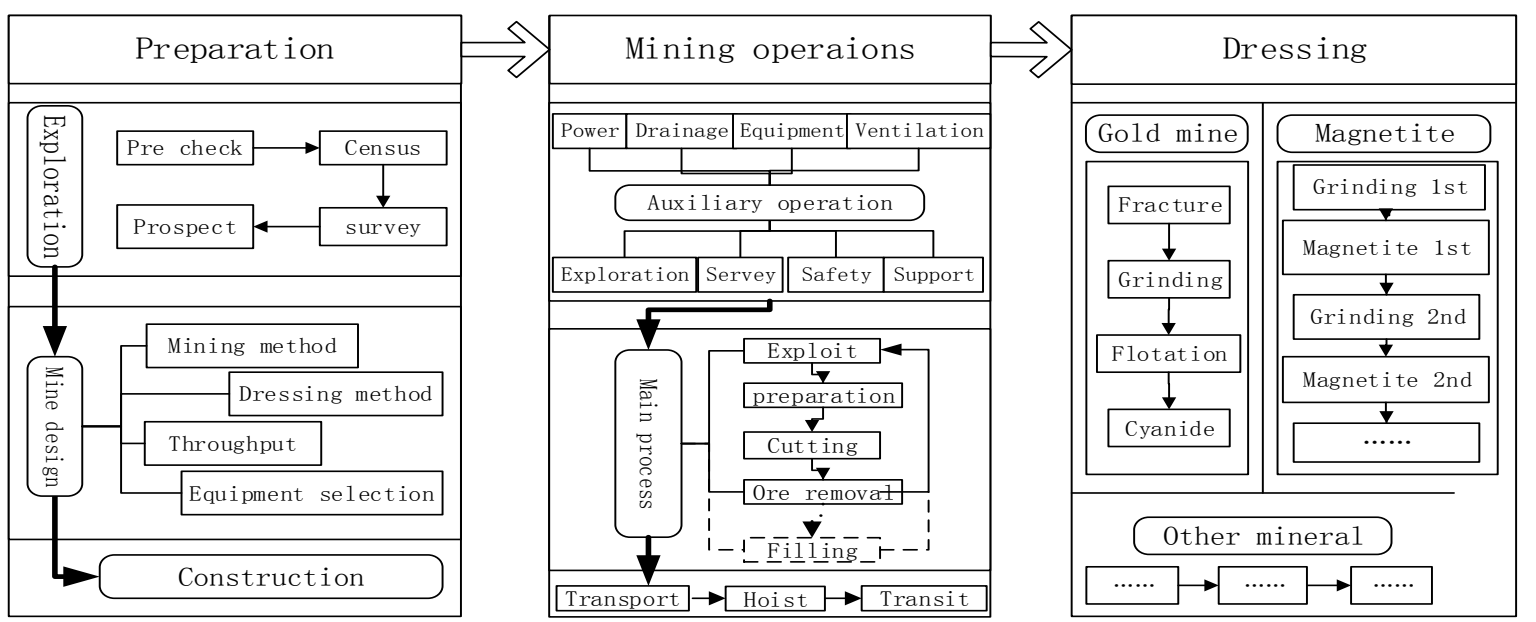

Figure 1. Mine production process

Mineral exploration and mine construction's main purposes are to provide resources and mining technical conditions to reduce the development risks and to maximize economic benefits. Solid mineral exploration work was divided into four stages: search, surveys, detailed investigation, and exploration.

Mining is an act, process, or work of mining mineral resources out of the crust and transporting them to the processing location or a place to be used. Deposit underground mining was divided into four stages: exploration, mining, cutting and stopping. In the process, it involved the related technology of mining, geology, surveying, machinery, computer and many other subjects. Mineral processing was defined as a process using gravity separation, flotation, and electrostatic separation according to the physical and chemical properties of the different minerals in the ore, separating the valuable minerals from gangue minerals, and the symbiosis of various valuable minerals separated as much as possible after ore crushing, while at the same time removing or reducing harmful impurities.

Among mining processes, the mining site mainly involved drilling, blasting, ventilation, mining and other sectors and process, as shown in Figure 2:

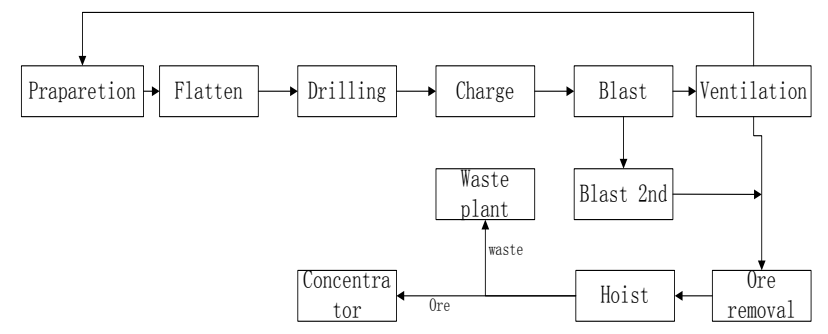

Figure 2. Flow chart of mining process
Based on the survey results, six kinds of major subject areas and fourteen kinds of class master data entities were identified: ore, personnel, materials, and other ten kinds of parameter data.

At present, because of the different definitions for material between the Design Department and the Materials Management Department, the User Development Management System did not directly use the definitions in the material management system. Consequently, the end user of User Development Management System had to redefine the material number. This undoubtedly caused a waste of resources.

Based on the twelve aspects of investigation in the Jinshandian Iron Mine, taking material for an example, problems of data resource can be summed up as follows:

1) Standards: the current coding standards have been developed and implemented, but there was no official release. The end user did not know the standards. For example, a screwdriver can also be called a bolt driver. Different end users defined different names.

(2) Management tools: due to the lack of master data management tools about material work had to rely on mail, telephone and QQ for approval, maintenance by hand;

(3) Organizational aspects: lack of organization about material at the operational level of the company and lack of professionalism of the business review led to the process of data audit, which was not standardized and affected the normal function of the information system;

(4) Regulation: Because of the lack of guides for material master data submission, it was difficult to complete material submission, which affects the reported accuracy;

(5) Work flow: there was only workflow for the audit process about the material, but a lack of workflow for material changes and failures; 
PAPER

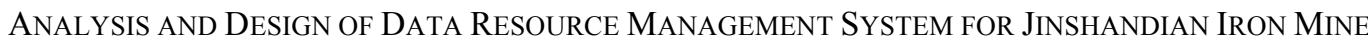

To solve the problems in standards, management tools, organization, regulation, and work flow, a data resource management system and a data resource management control system should be built.

\section{DESIGN PRINCIPLES AND SignifiCANCE OF DATA RESOURCE MANAGEMENT SYSTEM}

Data resource management was to optimize the data as an enterprise asset, including of protection, utilization, data availability, data integrity and data security management. In fact, data resource management was a system that focused on information system implementation. The purpose of this system was to integrate IT with business knowledge and advice through an effective combination of the organization, system, processes and strategies, realizing the informatization construction of enterprises with a full range of regulation. This would require senior authorization and collaboration in IT departments. The design principles were shown as follows:

1) To build a complete data resource management system architecture, including data integration, data processing, data applications and content management and security.

2) To provide accurate, continuous, real-time (Concise, Consistent and Current) information and data platform.

3) New ideas and technologies such as grid computing, virtualization, and on-demand computing must be able to adapt to the future development of data resource management needs and content with the practical proactive premise.

4) It must provide reusable information architecture with protection of existing achievements and investments.

According to DAMA International's definition of data resource management, data resource management consisted of data governance, data architecture, data development, data manipulation, data security, data quality, master data and reference data, metadata, and unstructured data, data warehouse, and business intelligence.

\section{The Overall Design of Data Resource MANAGEMENT SYSTEM}

Based on DAMA International's definitions and guidance for enterprise data management system's mature methodology for planning and design, this paper divided a data resource management system into six parts: information, resources, services, IT infrastructure, management and control systems, data security, and developed seven steps to build the system, including master planning, information architecture planning, service planning, resource planning, IT infrastructure planning, management and control system planning, and data security plan.

Below (see Figure 3) is a conceptual view of the data resource management system for planning:

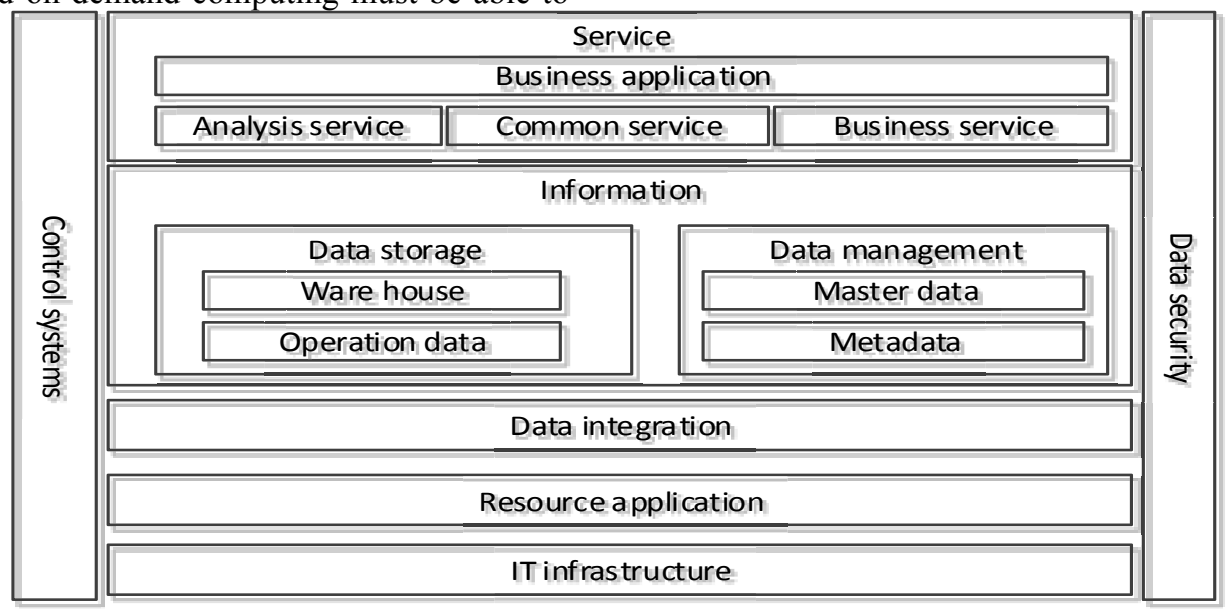

Figure 3. Conceptual view of the data resource management system

To describe the data resource management system clearly, data-related services provided by the resource management system were put together. Models with higher levels of abstraction were defined as the following functional areas.

Service: Based on two aspects of transaction, processing application and analysis application, the enterprise information service was set up. Multiplex public controls can ensure the development efficiency of the data resource management system and to reduce errors.

Information: Information can provide a unified data service for a data center. First of all, it should integrate the data resource to ODS. To support analytically complex applications for large and medium-sized enterprises, it needs a data warehouse.

Resource: This data resource management system contained multiple sources of data. In this respect these data were divided into external data from enterprise infor- mation systems and internal data from enterprise information. These data were divided into structured data, semi-structured data, and unstructured data in the variety of formats.

IT Infrastructure: Infrastructure was the basis of the resource management system application platform, including networks, servers, storage, and infrastructure software. It applied standardized products and virtualization technology for construction applications.

Data Security: The security architecture for the data resource management system and technical implementation was based on safety technology, including application security and database security as well as storage, security, and resource access security.

Control Systems: The data resource management control system was the complete mechanism of enterprise data assets that organically combined its owner, administration, and data users and the management tools associ- 
PAPER

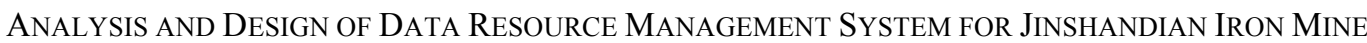

ated with them. The data resource management control system was divided into the organization, system, process, and evaluation. It consisted of establishing the data resource management control structure of the organization, clearly regulating the organization's division of responsibilities, and determined control of the main activities of the organization. It also included the implementation of the unified data resource management methods and processes. Evaluation was used to monitor implementation of the system and to improve the performance-evaluation system.

\section{CONCLUSION}

The construction of the data resource management system sorted out the enterprise information resource status of the Jinshandian Iron Mine and provided a set of scientific and complete solutions for the data resources. At the same time, from the enterprise's long-term development perspective, a data resource management platform was built, and the development of an enterprise business management system was achieved, solving the data resource dispersed repeats; caliber inconsistencies; and sharing difficulties fundamentally caused by the information island problem, which promoted the data integration and data sharing of information system and improved the information service ability.

\section{REFERENCES}

[1] Risto Silvola, Harri Haapasalo. Managing one master data - challenges and preconditions $[\mathrm{J}]$. Industrial management data systems,2011， 111(1/2):146-162. http://dx.doi.org/10.1108/02635 $\underline{571111099776}$

[2] Boris Otto. How to design the master data architecture: Findings from a case study at Bosch $[\mathrm{J}]$. International journal of information management, 2012, 32(4): 337-346. http://dx.doi.org/10.1016/j.ijin fomgt.2011.11.018

[3] Kathleen Petri Seiler, Nicole E. Body combe, Ted Hawkins et al Master Data Management: Getting your House in Order [J].Combinatorial chemistry high throughput screening, 2011, 14(9):749-756. http://dx.doi.org/10.2174/138620711796957189

[4] WILLIAM MCKNIGHT. Master Data Management and the Elephant [J]. Information management, 2009, 19(8):40-41.

[5] Batcheller, JK. Automating geospatial metadata generation - An integrated data management and documentation approach [J]. Computers geosciences, 2008, 34(4):387-398. http://dx.doi.org/10.1016/j.cageo.2007.04.001

[6] O-hoon Choi, Jung-eun Lim, Dong-hyun Lee. A multimedia contents management system based on a metadata-net in home network [J]. IEEE Transactions on Consumer Electronics, 2008, 54(2):468-473. http://dx.doi.org/10.1109/TCE.2008.4560116

\section{AUTHOR}

YunSen Wang is with the College of Resources and Civil Engineering, Northeastern University, Shenyang, CO 110179 China (e-mail: cdcloud@163.com).

Submitted, 09 March 2015. Published as resubmitted by the author on 09 April 2015. 